\title{
ADJUDICACIÓN DE CONTRATOS PARA LA EXPLORACIÓN Y EXTRACCIÓN DE HIDROCARBUROS. PROCEDENCIA DEL AMPARO
}

\author{
ADJUDICATION OF CONTRACTS FOR THE EXPLORATION AND \\ EXTRACTION OF HYDROCARBONS PROCEEDING OF THE APPEAL
}

\section{PAOLA RODRÍGUEZ ROMO ${ }^{1}$}

RESUMEN: El objetivo de este artículo es analizar la procedencia del amparo respecto de los actos realizados para adjudicar contratos para la exploración y extracción de hidrocarburos, en el marco de la reforma energética. Para tal efecto, el artículo se divide en cinco apartados: la primera parte encaminada a contextualizar al lector y detallar la estructura del presente artículo; la segunda diseñada para identificar las diversas actuaciones que se realizan para la adjudicación de contratos petroleros y de esa forma distinguir entre aquellos actos previos a la licitación y aquellos realizados durante ésta; el tercero, dedicado a determinar si el amparo es procedente y en su caso, identificar los posibles actos objeto de impugnación; mientras que el cuarto va dirigido a analizar los sujetos que pueden promover dicho medio de impugnación, finalizando con el último apartado, dedicado a las conclusiones del presente artículo.

PALABRAS CLAVE: Reforma energética, contratos, actos intraprocesales, licitación pública, adjudicación, amparo, amparo indirecto, quejoso.

ABSTRACT: The purpose of this article is to analyze the origin of amparo regarding to the executed acts in order to adjudge contracts with the objective of exploring and extracting hydrocarbons in the legal framework of Mexican's energy reform. In order to analyze the topic, this article is divided in five sections: the first one aimed at contextualizing the reader and to detail the structure of this paper, the second one is designed in order to identify the several situations that are performed for the adjudication of oils contracts and in this

1 Maestra y Licenciada en Derecho por la UNAM. Subdirectora en la Dirección General de Contratos Petroleros de la Secretaría de Energía. Contacto: <romius19@gmail.com>. 
way to distinguish between those previous acts to the bidding and those carried out during it, the third one, is dedicated to determine if the amparo is appropriate and, if it is, to identify the possible acts that are object of the challenge and the fourth section is aimed at analyzing the subjects than can promote this ways of challenge and this paper ends with the last section, dedicated to the conclusions of this article.

KEYWORDS: Energy reform, contracts, acts inter process, public tender, award, amparo, indirect amparo, complainer.

Sumario. I. Objetivo y estructura del artículo; II. Adjudicación de los Contratos: distinción entre actos previos a la licitación y actos de la licitación; III. Procedencia del amparo; IV. Legitimados para promover el juicio de amparo; V. Conclusiones; VI. Bibliografía.

\section{i. Objetivo y estructura del artículo}

7 l objetivo del presente artículo es analizar y determinar si el amparo es procedente respecto a los actos que se llevan a cabo para la adjudicación de contratos. Para ello, resulta indispensable identificar y analizarlos, a fin de que el estudio de la procedencia del amparo sea casuística, esto es, en atención a cada uno de dichos actos.

Para tal efecto, el primer apartado del presente artículo tiene como fin contextualizar el tema, lo cual permitirá conocer el origen de la licitación, como uno de los procedimientos previstos en la normatividad en la materia, para la adjudicación de contratos. Realizado lo anterior, el segundo objetivo de este apartado será la descripción de los diversos actos que la autoridad realiza para la adjudicación de contratos, mediante la distinción entre los que se desarrollan de manera previa al inicio del procedimiento de licitación, respecto de aquellos que se llevan a cabo durante ésta.

La identificación de dichos actos permitirá un mejor entendimiento de la procedencia del amparo, pues de esta forma es posible señalar detalladamente los actos que son susceptibles de ser impugnados mediante dicha vía y aquellos que deberán ser descartados. 
Finalmente, una vez expuesta la procedencia del amparo, resulta indispensable identificar a los sujetos legitimados para accionar dicho medio de defensa. Para ello resultará útil la distinción de los actos previos y los desarrollados durante la licitación arriba mencionada, ya que la existencia de estas dos etapas implica también la existencia de actores distintos que se ubican en supuestos diferentes que habrán de ser analizados, para determinar su legitimación.

II. Adjudicación de los contratos: distinción entre ACTOS PREVIOS A LA LICITACIÓN Y ACTOS DE LA LICITACIÓN

Mediante el Decreto por el que se reforman y adicionan diversas disposiciones de la Constitución Política de los Estados Unidos Mexicanos, en Materia de Energía, publicado en el Diario Oficial de la Federación, el 20 de diciembre de 2013, se modificaron entre otros artículos, el 27 para adicionar el párrafo séptimo, el cual señala que la Nación llevará a cabo las actividades de exploración y extracción del petróleo y demás hidrocarburos mediante asignaciones a empresas productivas del Estado o a través de contratos con éstas o con particulares.

A fin de normar los contratos a los que alude el Decreto, el 11 de agosto de 2014 se publicó en el medio de circulación oficial referido, la Ley de Hidrocarburos reglamentaria entre otros, del artículo 27 constitucional, la cual establece que el Ejecutivo Federal a través de la Comisión Nacional de Hidrocarburos ${ }^{2}$ celebrará contratos para

2 El Decreto de la Reforma Energética adiciona un párrafo octavo al artículo 28 constitucional para establecer la existencia de la Comisión Nacional de Hidrocarburos, como un órgano regulador coordinado en materia energética, la cual en términos del artículo transitorio Décimo Segundo cuenta con personalidad jurídica propia y autonomía técnica y de gestión para emitir sus propios actos y resoluciones. 
explorar y extraer hidrocarburos. Para la selección del contratista, ${ }^{3}$ se llevará a cabo un procedimiento de licitación conducido por dicho órgano, mismo que iniciará con la publicación de la convocatoria correspondiente. ${ }^{4}$

En términos de dicha Ley, el contrato es el acto jurídico que suscribe el Estado Mexicano, a través de la Comisión, por el que se conviene la exploración y extracción de hidrocarburos en un área contractual y por una duración específica.

Si bien, el proceso de licitación constituye uno de los mecanismos previstos en la ley reglamentaria para la celebración de contratos que permitan explorar y extraer hidrocarburos; esta norma también prevé otros mecanismos que comparten dicho objeto, tales como la migración, procedimiento mediante el cual Petróleos Mexicanos y las demás empresas productivas del Estado - Asignatarios- solicitan a la Secretaría de Energía celebrar un contrato respecto de una asignación ${ }^{5}$ previamente otorgada, para lo cual el solicitante deberá cubrir los requisitos previstos en la normatividad.

El contrato que se celebre como resultado del proceso de migración referido, como se ha señalado, también tendrá como efecto la exploración y extracción de hidrocarburos, actividades petroleras que se entiende ya venía realizando la empresa productiva en cues-

${ }^{3}$ En términos del artículo 4 fracción $\mathrm{X}$ de dicha Ley, el Contratista puede ser Petróleos Mexicanos, cualquier otra empresa productiva del Estado o Persona Moral, que suscriba con la Comisión un contrato, ya sea de manera individual o en consorcio o asociación en participación, en términos de la Ley de Ingresos sobre Hidrocarburos.

${ }^{4}$ De los artículos 15 y 23 de la Ley de Hidrocarburos se desprende que el proceso para la adjudicación de los contratos iniciará con la publicación de la convocatoria en el Diario Oficial de la Federación.

${ }^{5}$ La asignación constituye el acto jurídico administrativo mediante el cual el Ejecutivo Federal otorga exclusivamente a un asignatario el derecho para realizar actividades de exploración y producción de hidrocarburos en el àrea de asignación, por una duración específica. 
tión al amparo de una asignación, pero que ahora deberá desarrollar en los términos previstos en el contrato que para tal efecto celebre. Ambos procedimientos también pueden ser explicados como las opciones con las que, cuenta el Estado derivado de la reforma energética, para el desarrollo de sus recursos naturales, ya que previo a dicha reforma, sólo la Nación a través de Petróleos Mexicanos y sus organismos subsidiarios, podía llevar a cabo la exploración y explotación del petróleo y las demás actividades estratégicas previstas en nuestra norma fundamental. ${ }^{6}$

Apuntado lo anterior, conviene señalar que para efectos del presente artículo, el estudio se centrará en el primero de los procedimientos referidos, esto es, el procedimiento de licitación para la adjudicación de contratos, para así determinar la procedencia del amparo.

En términos de la ley reglamentaria, la licitación inicia con la publicación de la convocatoria y las bases de licitación, documentos de los que se desprende toda la información sobre el proceso licitatorio, su objeto, las etapas que lo componen y las reglas bajo las cuales se conducirán así como las características de las áreas contractuales a licitar.

Como más adelante se analizará, la información necesaria para la publicación de los documentos señalados debe ser proporcionada por la Secretaría de Energía, lo cual implica llevar a cabo, de manera previa al proceso de licitación, diversas acciones en colaboración con otras dependencias y entidades ${ }^{7}$ a fin de obtener los insumos necesarios para tal efecto, entre los que destacan la selec-

6 Estas actividades se realizaban al amparo de lo dispuesto en la Ley Reglamentaria del artículo 27 constitucional en el ramo del petróleo, misma que fue abrogada el 11 de agosto de 2014, con la entrada en vigor de la Ley de Hidrocarburos.

7 Las principales dependencias y entidades con las que la Secretaría de Energía debe coordinarse para el efecto descrito son la Secretaría de Economía, la Secretaría de Hacienda y Crédito Público, la Comisión Nacional de Hidrocarburos y la Comisión Federal de Competencia Económica. 
ción del modelo de contratación así como el diseño de los contratos a licitarse.

Así, es posible apreciar dos momentos para la adjudicación de contratos: El primero, previo al inicio de la licitación y el segundo, la licitación en sí.

\section{Procedimiento PREVIO a La Licitación}

Como se mencionó, los actos que se desarrollan durante esta etapa tienen como finalidad que la Secretaría de Energía se allegue de los insumos necesarios para solicitar la publicación de una convocatoria y así, dar inicio a una licitación; insumos que deberá remitir a la Comisión, órgano regulador encargado de llevar a cabo dicho procedimiento, siendo los siguientes:

- La identificación de las áreas contractuales ${ }^{8}$ a ser licitadas;

- Los términos y condiciones técnicos;

- Los lineamientos técnicos;

- Las condiciones económicas relativas a los términos fiscales de los contratos, así como aquéllas que deberán observarse en el proceso de licitación, que establezca la Secretaría de Hacienda conforme a la normatividad aplicable, y

- La opinión que emita la Comisión Federal de Competencia Económica respecto a los criterios de precalificación ${ }^{9}$ y el mecanismo de adjudicación.

8 En términos de la Ley de Hidrocarburos, el área contractual es la superficie y profundidad determinadas por la Secretaría de Energía, así como las formaciones geológicas contenidas en la proyección vertical en dicha superficie para dicha profundidad, en las que se realiza la exploración y extracción de hidrocarburos a través de la celebración de contratos.

9 El artículo 18 de las Disposiciones administrativas en materia de licitaciones de contratos para la exploración y extracción de hidrocarburos, los define como auqellos elementos para acreditar la experiencia, capacidad técnica, financiera, 
Asimismo, la normatividad en la materia establece el procedimiento a seguir para la obtención de dichos insumos, como se muestra en el gráfico siguiente:

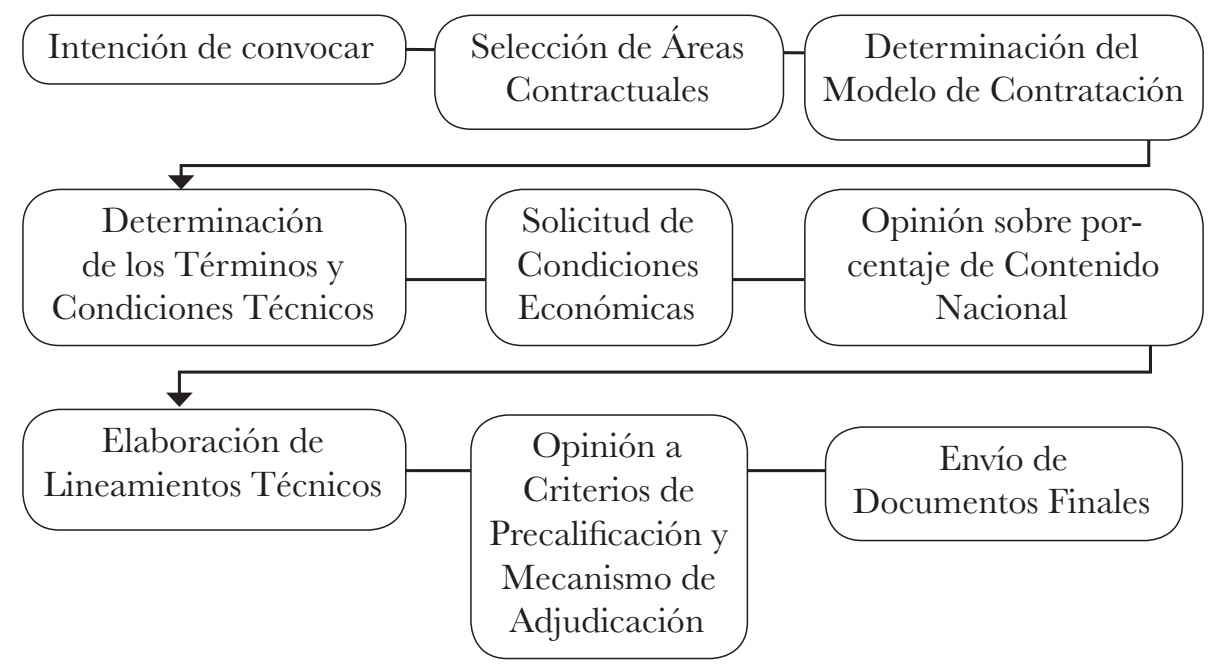

Figura. Actos previos a la licitación.

Procedimiento que a continuación de describirá:

Primeramente, conviene señalar que es un procedimiento conducido por la Secretaría de Energía, bajo la lógica de que los primeros actos son condiciones sine qua non de los subsecuentes, esto es, que la realización de los primeros actos condiciona la existencia de los siguientes:

- El primer acto consiste en notificar la intención de convocar a una licitación, tanto a la Secretaría de Hacienda como a la Comisión. Lo anterior, al ser ésta última la autoridad convocante y la responsable de llevar a cabo el procedimiento de licitación en tanto que la primera dependencia es la autoridad encargada de establecer las

jurídica y operativa establecidos por la Secretaría de Energía en los Lineamientos Técnicos que emita para cada proceso de licitación. 
condiciones económicas que formarán parte integral de los contratos.

- La selección de las áreas contractuales que serán objeto de una licitación constituye unas de las más importantes decisiones que debe tomar la Secretaría de Energía, puesto que es el primer elemento a considerar por el sector para definir su participación en un determinado proceso licitatorio.

Como podrá apreciarse, de los nueve procesos licitatorios a la fecha desarrollados por la Comisión, el mayor éxito se ha presentado en aquellas licitaciones cuyas áreas contractuales cuentan con el mayor número de recursos prospectivos, es decir, con el mayor volumen de hidrocarburos estimado, a una cierta fecha, de acumulaciones que si bien aun no se descubren, se infieren y se estiman como potencialmente recuperables.

De ahí la necesidad de contar con la asistencia técnica de la Comisión, para la selección de las áreas contractuales, al ser dicho órgano el facultado por ley para el acopio, resguardo, uso, administración y actualización de la información que se obtenga o haya obtenido de actividades tales como la exploración y extracción de hidrocarburos.

Además de contar con la asistencia técnica referida, la Secretaría habrá de sujetarse a lo previsto en el Plan Quinquenal, que constituye el documento indicativo en el que se establece la propuesta de las áreas contractuales a licitar así como sus características generales, en un periodo de cinco años. ${ }^{10}$

10 El Plan Quinquenal puede ser consultado en el siguiente vínculo electrónico: <https://www.gob.mx/cms/uploads/attachment/file/41843/Plan_Quinque nal.pdf> [04-07-2018]. Por disposición legal, la ejecución de dicho Plan debe ser evaluada anualmente, para en su caso realizar las adiciones o modificaciones que se requieran, como la valoración de las áreas contractuales propuestas por la industria, sobre las cuales exista interés. 
- La modalidad de contratación alude a los diversos tipos de contratos que pueden celebrarse para la exploración y extracción de hidrocarburos, que para el caso de México son los siguientes: de servicios, de utilidad o producción compartida, y de licencia. ${ }^{11}$

$\mathrm{Al}$ igual que la selección de las áreas contractuales, esta decisión implica un análisis a fondo de las ventajas y desventajas que puede representar para el Estado la elección de uno u otro tipo de modalidad, ya que involucra beneficios y costos tanto para el Estado como para el contratista. ${ }^{12}$

Por citar un ejemplo, si bien la modalidad de licencia representa para el Estado el menor riesgo en el desarrollo del proyecto, ya que éstos son asumidos por el contratista; sí puede implicarle desventajas, principalmente de carácter comercial, mismas que van directamente relacionadas con la información disponible de las áreas contractuales y la maximización de los recursos, entre menos información exista, mayor incertidumbre respecto a los resultados esperados del proyecto. ${ }^{13}$

Por otra parte, de acuerdo con el procedimiento descrito, la Secretaría debe contar con la opinión tanto de la Comisión como de la Secretaría de Hacienda, mismas que si bien no son vinculantes para efectos de la determinación que adopte dicha dependencia constituyen un requisito exigido por la ley de la materia. ${ }^{14}$

11 El artículo 18 de la Ley de Hidrocarburos establece de manera expresa estas cuatro modalidades de contratación.

12 Contratos Petroleros. Cómo leerlos y entenderlos. OpenOil, traducción al español 2013.

13 Radon, Jenik, The ABCs of Petroleum Contracts: License-Concession Agreements, Foint Ventures, and Production-sharing Agreements, New York, Covering Oil, p. 65.

14 Si bien dichas opiniones no son vinculantes, en el caso de la Cuarta Convocatoria de la Ronda Uno, la Secretaría de Energía modificó su determinación respecto al modelo de contratación, ello en atención a elementos tales como la opinión emitida por la Comisión Nacional de Hidrocarburos, en el sentido de que 
- Definido el modelo de contratación, procede la determinación de los términos y condiciones técnicos, para lo cual solicitará de manera simultánea a la Secretaría de Hacienda el establecimiento de las condiciones económicas relativas a los términos fiscales, las cuales constituirán parte integral del contrato.

- La determinación de la modalidad de contratación incidirá directamente en el contenido del contrato, puesto que los riesgos asumidos por cada parte, propios de la naturaleza de cada modalidad habrán de verse reflejados en las obligaciones contractuales y los mecanismos diseñados para garantizar su cumplimiento.

- Asimismo, deberá solicitar a la Secretaría de Economía su opinión sobre el porcentaje mínimo de contenido nacional que se establecerá en los contratos. Lo anterior a fin de que la meta propuesta se vea reflejada en los bienes y servicios contratados, la mano de obra nacional y de trabajo calificada, la capacitación de la mano de obra nacional, la inversión en infraestructura física local y regional y la transferencia de tecnología.

- Una vez recibidas las condiciones económicas, la Secretaría elaborará los lineamientos técnicos que se observarán en el proceso de licitación. Cabe señalar que dichos lineamientos forman parte de las bases de licitación, mismas que podrán ser consultadas en la página de Rondas México.

- Asimismo, solicitará a la Comisión Federal de Competencia Económica su opinión respecto a los criterios de precalificación y el mecanismo de adjudicación propuestos, para determinar si se apegan a las mejores prácticas de la

resultaba una mejor opción el modelo de licencia que el de producción compartida propuesto. 
industria y a los principios generales en materia de libre concurrencia y competencia económica. ${ }^{15}$

- Concluido lo anterior, la Secretaría remitirá a la Comisión los documentos finales para la publicación de la convocatoria correspondiente.

\section{Procedimiento de licitación}

Como se mencionó, la licitación es el procedimiento mediante el cual, el Estado mexicano a través de la Comisión, adjudica contratos. Los actos que componen dicho procedimiento son los siguientes: 1) publicación de la convocatoria; 2) publicación de las bases de licitación ${ }^{16}$; 3) acceso a la información del cuarto de datos ${ }^{17}$; 4) aclaraciones a las bases de licitación; 5) precalificación; 5) en su caso, visitas al área contractual; 6) presentación y apertura de propuestas; 7) adjudicación y fallo y, 8) suscripción del contrato. A continuación, se describe de manera sucinta dicho procedimiento:

- Como se señaló, la publicación de la convocatoria y las bases se realiza en un solo acto. La versión íntegra de las bases de licitación se publica en la página de Rondas México.

- El acceso a la información del cuarto de datos constituye una etapa que deben acreditar los interesados en participar

15 Esta opinión tampoco es vinculante para la Secretaría de Energía; no obstante, en caso de que dicha Comisión realice observaciones a los documentos objeto de la opinión, éstas son analizadas por dicha dependencia y la Secretaría de Hacienda, notificándole la opinión que en conjunto estimen procedente.

16 En términos del artículo 2 fracción I de las Disposiciones Administrativas, es el documento en el cual se pone a disposición de los interesados, los requisitos y formalidades que deben cubrir para participar en un determinado concurso público de libre participación contemplado en la ley.

17 En términos de las bases de licitación, es un repositorio de información usado para el almacenamiento y distribución de información relacionada con las áreas contractuales objeto de una licitación. 
en una licitación para efectos de continuar en el procedimiento. Para el acceso resulta indispensable adquirir una licencia de uso que tiene un costo, previsto en las bases. Entre la publicación de la convocatoria y el cierre del periodo al cuarto de datos se establece un plazo para que los interesados y licitantes puedan verificar la información de las áreas contractuales.

- Una vez acreditada la etapa de acceso a la información del cuarto de datos, los interesados en la licitación deben solicitar su inscripción a la Comisión junto con el pago del aprovechamiento correspondiente.

- La etapa de aclaraciones, cuya conformación dependerá de cada licitación, suele comprender tres periodos: El primero, para solicitar aclaraciones a las bases y el cuarto de datos; el segundo, respecto a los criterios de precalificación y conformación de licitantes y, el tercero relacionado con el contrato, la apertura de propuestas y el fallo.

- Junto con el cierre de la etapa de aclaraciones, el calendario de las bases generalmente prevé la publicación de la versión final de las bases y el contrato, lo que implica que dichos documentos ya no podrán ser objeto de modificaciones. ${ }^{18}$

- La etapa de precalificación incluye la recepción de documentos de las empresas, la revisión documental y en su caso, la elaboración de prevenciones o bien, la solicitud de información adicional a los interesados. El calendario de

18 En las bases de licitación se prevé la posibilidad de que la convocante pueda modificarlas, mismas que deberán ser publicadas en el Diario Oficial de la Federación y en la página oficial. Estas modificaciones pueden ser resultado de la etapa de aclaraciones. Una vez concluido el periodo para inscribirse a la licitación, no se podrán llevar a cabo modificaciones sustanciales a las bases, sus anexos y formatos, así como al contrato. Las modificaciones sustanciales son aquellas que contribuyen a fortalecer los principios legales que regulan la licitación. 
las bases prevé una semana para que la autoridad elabore informes con los resultados de la precalificación.

- Una vez publicada la lista de empresas precalificadas, se otorga una semana a los licitantes para agruparse y presentar la información para la conformación de licitantes. Esta etapa se realiza en dos semanas, la primera para la recepción de documentos y la segunda, para la revisión de los mismos.

- Finalmente, entre la publicación de los resultados de conformación de licitantes y el acto de apertura de propuestas se establece un plazo el cual permite a las empresas gestionar las garantías. ${ }^{19}$

Tal como puede apreciarse, son diversos los actos que deben llevarse a cabo para que pueda dar inicio una licitación, lo cual involucra a diversas autoridades así como actos de distinta naturaleza. Lo anterior, será relevante para determinar la procedencia del amparo, de ahí que el análisis a realizarse sea casuístico.

\section{ili. Procedencia del amparo}

Una vez identificadas las diversas actuaciones para la adjudicación de los contratos, corresponde entrar al estudio de la procedencia del amparo, el cual partirá de lo dispuesto en la ley de la materia (hidrocarburos) así como de la ley aplicable a este medio de impugnación.

A manera de introducción, se señalarán algunas características del juicio de amparo. Así, en primer lugar se apunta que este juicio es, como lo señala Ferrer-Mac Gregor "un mecanismo de protección

19 Se alude a la garantía de seriedad consistente en una carta de crédito otorgada por el licitante a favor de la Comisión para garantizar su propuesta y, en caso de resultar licitante ganador, garantizar la firma del contrato que le sea adjudicado, en los términos establecidos en las bases de licitación. 
específica para salvaguardar los derechos fundamentales dentro de los sistemas de control de la constitucionalidad de leyes." 20

El amparo constituye un medio de defensa con que cuenta el gobernado para hacer valer y dar efectividad, consecuentemente, a los derechos que la constitución y los tratados internaciones le reconocen.

Si bien, la ley que regula el juicio de amparo ha sido objeto de diversas modificaciones, importante mención merecen la reforma constitucional en materia de derechos humanos del 6 de junio de 2011 y la nueva Ley de Amparo publicada en el Diario Oficial, el 2 de abril de 2013. En la primera de ellas, se introduce la procedencia del amparo por violaciones a los derechos humanos previstos en los tratados internacionales de los que el Estado mexicano sea parte así como por omisiones en que incurran las autoridades.

Asimismo, dicha reforma introduce los principios pro persona $\mathrm{y}$ el de interpretación conforme ${ }^{21}$, como ejes rectores para la interpretación y aplicación de las normas jurídicas, el primero de ellos concebido como un elemento definitorio de la interpretación conforme, consistente en la aplicación de la norma sobre derechos humanos que sea más protectora para la persona o aquella que se aplicará de manera preferente ante derechos que se encuentren en conflicto. El segundo consiste en interpretar las normas relativas a los derechos humanos de conformidad con la Constitución, esto es, determinar el contenido de dichas normas. ${ }^{22}$

20 Ferrer-Mac Gregor Poisot, Eduardo, Panorámica del derecho procesal constitucional y convencional, Madrid, Marcial Pons-IIJ, 2017, 2a reimp., p. 303.

21 Como resultado de un criterio recientemente adoptado por el Poder Judicial de la Federación, se desprende que además de ser considerado un principio, también es concebido como un método hermenéutico, así como una técnica de interpretación. Tesis: I.1o.A.E.78 K (10a.), Gaceta del Semanario Fudicial de la Federación, Décima Época, $t$. II, Julio de 2018, p. 1503.

22 Caballero Ochoa, José Luis, La cláusula de interpretación conforme y el principio por persona (Artículo $1^{a}$ segundo párrafo de la Constitución), Ciudad de México, IIJ, 2011, p. 169. 
La segunda incorpora nuevas figuras al texto de la ley, tales como el amparo adhesivo y los intereses legítimo, individual o colectivo. ${ }^{23}$

Si bien las reformas aludidas modificaron sustancialmente el juicio de amparo, los principios procesales que lo rigen se conservan en esencia, siendo los siguientes:

- Prosecución judicial. El amparo es un proceso jurisdiccional, en consecuencia, está sujeto a las formas y principios que rigen todo juicio tales como la del debido proceso.

- Instancia de parte agraviada. El juicio de amparo sólo puede iniciar cuando se ejercita la acción por la parte que resintió el agravio quien deberá demostrar tener un interés jurídico o legítimo. Lo anterior, implica que el amparo no puede iniciar de oficio, por lo que el quejoso deberá acudir ante los tribunales a hacer valer su derecho. Dicho principio también se proyecta a todas las etapas que componen el juicio, pues tal como se desprende de la Ley, cada una de las etapas que lo componen deben ser instadas por la parte quejosa.

Este principio también presupone la existencia de un agravio personal. Previo a la reforma del 6 de junio de 2011, para la procedencia del amparo se exigía la existencia de una afectación al interés jurídico; sin embargo, con la entrada en vigor de dicha reforma se reconoce de manera expresa el interés legítimo, que como se verá con posterioridad, para acreditarlo no resulta necesario demostrar la existencia de una afectación real y presente a la esfera jurídica de los derechos del tutelado. ${ }^{24}$

23 Toda la información sobre las reformas aludidas puede ser consultada en la página oficial de la Suprema Corte de Justicia de la Nación: <http://wrww2.scjn.gob. $m x /$ red/constitucion/inicio.html> [10-agosto-2018]

24 Si bien a nivel jurisprudencial ya se reconocía la existencia del interés legítimo, con la entrada en vigor de la reforma señalada, se reconoce su procedencia en el texto de la ley. 
- Relatividad de las sentencias. Conocido también como "Fórmula Otero", este principio implica que la sentencia de amparo sólo tiene efectos respecto de la persona que promovió el juicio de garantías. No obstante, con la entrada en vigor de la reforma multicitada se incorpora la declaratoria general de inconstitucionalidad, lo que implica que si mediante jurisprudencia, la Suprema Corte de Justicia de la Nación declara, de manera firme, la inconstitucionalidad de una norma general y en el plazo que la ley otorga no se subsana la irregularidad por el órgano que la expidió, la corte emitirá la declaratoria referida cuyo efecto será anular la norma en cuestión.

La anterior constituye una excepción al principio general consistente en que los efectos benéficos de la sentencia de amparo sólo pueden ser resentidos por el actor.

- Definitividad. Este principio presupone que quien promovió el amparo agotó, previamente, los recursos y medios de defensa ordinarios que podrían modificar o revocar el acto reclamado, los cuales son previstos por las disposiciones que regulan el acto objeto de impugnación. Lo anterior, en razón de la naturaleza del juicio de amparo, que no constituye una instancia más dentro de los procesos ordinarios sino una de carácter excepcional. No obstante, Ferrer Mac-Gregor ${ }^{25}$ señala algunas excepciones a dicho principio, a saber:

- Normas generales.

- Violaciones directas a la Constitución.

25 Ferrer-Mac Gregor Poisot, Eduardo, El nuevo juicio de amparo y el proceso penal acusatorio, México, UNAM-IIJ, 2013, 1ª Edición, pp. 23 y ss. 
- Actos administrativos que por el medio de defensa ordinario no puedan suspenderse con iguales o mayores alcances y facilidad que en el amparo.

- Terceros extraños al juicio o las partes asimilables a ellos.

- Los casos de extrema gravedad, entre ellos la desaparición forzada de personas, que prevé el artículo 15 de la Ley.

- Estricto derecho y suplencia de la queja. Este principio rige la actuación del juzgador más que el juicio de amparo en sí, ya que supone una técnica que lo obliga a ceñirse expresamente a los conceptos de violación o agravios planteados por el quejoso. Por tanto, la suplencia se la queja sólo operará en aquellos casos previstos en la Ley. ${ }^{26}$

- Mayor beneficio. El juzgador habrá de interpretar y aplicar la ley en el sentido que otorgue el mayor beneficio jurídico al quejoso.

Finalmente, resta decir que la Ley prevé dos tipos de amparo: directo e indirecto. El primero también llamado unïnstancial, el cual procede contra sentencias definitivas, laudos y resoluciones que pongan fin a un juicio, dictadas por tribunales judiciales, administrativos, agrarios o del trabajo, cuando la violación se cometa en ellas o durante el procedimiento, y en este último caso, afecte las defensas del quejoso trascendiendo al resultado del fallo.

El amparo indirecto, también llamado biinstancial procede contra normas generales, actos administrativos, actos judiciales (fuera, durante o después de concluido), actos que afecten a terceros extraños, omisiones del Ministerio Público en la investigación de los delitos así como respecto de las resoluciones que emita, inhibitoria o declinatoria y, normas generales, actos u omisiones de la Comi-

26 Salgado Ledesma, Eréndira, Manual de Derecho Procesal Constitucional, Ciudad de México, Porrúa, 2011 , p. 82. 
sión Federal de Competencia Económica y del Instituto Federal de Telecomunicaciones.

Una vez expuesto lo anterior, procederemos a analizar la procedencia del amparo respecto de los actos realizados de manera previa y durante el procedimiento de licitación. En tal sentido, conviene señalar que por disposición expresa de la Ley de Hidrocarburos, el amparo indirecto resulta procedente con relación a ciertos actos, para lo cual será útil la distinción realizada en el apartado anterior.

En efecto, dicha Ley establece de manera expresa que contra las resoluciones mediante las cuales se asigne al ganador o se declare desierto el proceso de licitación de contratos únicamente procederá el juicio de amparo indirecto ${ }^{27}$.

$\mathrm{Al}$ respecto, se advierte que el fallo es el acto que emite la autoridad responsable de conducir el procedimiento de licitación-Comisión Nacional de Hidrocarburos - el cual contiene los resultados de éste, esto es, las propuestas que fueron desechadas, el o los nombres de los licitantes ganadores así como el plazo para la suscripción del contrato. En consecuencia, el fallo constituye el acto al que alude la ley en cita respecto del cual procede el amparo indirecto, puesto que constituye la resolución definitiva.

Lo anterior, también es retomado por la Ley de los Órganos Reguladores Coordinados en Materia Energética, la cual establece expresamente que cuando se trate de resoluciones de los Órganos Reguladores, carácter que tiene la Comisión referida, emanadas de un procedimiento seguido en forma de juicio, sólo podrá impugnarse la que ponga fin al mismo por violaciones cometidas en la resolución o durante el procedimiento.

Ahora bien, de los criterios jurisprudenciales emitidos por nuestro máximo tribunal se desprende que la licitación pública constituye un procedimiento seguido en forma de juicio. ${ }^{28}$ De ahí que, la

27 Así lo dispone de manera expresa el artículo 25 de la Ley de Hidrocarburos.

28 Tesis: 2a./J. 115/2015 (10a.), Gaceta del Semanario Judicial de la Federación, Décima Época, $t$. I, Septiembre de 2015, p. 473. 
licitación pública es el procedimiento al cual alude esta ley, respecto de la que sólo podrá impugnarse el fallo que pone fin a dicho procedimiento, estableciendo la posibilidad de hacer valer violaciones cometidas durante dicho procedimiento.

Como se advierte, la legislación en la materia identifica el acto contra el cual procede el amparo indirecto, así como la improcedencia de dicho juicio y la de cualquier otro recurso ordinario cuando se promueva o interponga contra los actos intraprocesales ${ }^{29}$ realizados durante dicho procedimiento.

Lo anterior, está expresamente previsto en el artículo 27 de la Ley de Órganos Reguladores citada, que establece la improcedencia de cualquier recurso ordinario o constitucional contra los actos intraprocesales.

Resulta importante detenerse en este punto a fin de identificar los actos intraprocesales a los que alude la disposición en cita. Por exclusión, a primera vista los actos previos a la licitación no pueden tener tal carácter ya que la ley alude a aquellos que se desarrollan durante el procedimiento de licitación, como se analizará a continuación:

\section{Actos previos al inicio del procedimiento de Licitación}

Dichos actos ya fueron analizados con anterioridad, por lo que basta decir que al ser actuaciones previas al inicio de la licitación, no pueden constituir aquellos a los que la ley alude como actos intraprocesales al no desarrollarse dentro del procedimiento de licitación.

$29 \mathrm{Al}$ respecto, del artículo 107 fracción II inciso b) de la Ley de Amparo así como de la jurisprudencia emitida por nuestro máximo tribunal se desprende la procedencia del juicio de amparo contra actos intraprocesales, cuando el acto reclamado en cuestión implique dejar en estado de indefensión al quejoso, situación que no puede diferirse hasta el dictado de la resolución final: Tesis: PC.XXXIII. CRT J/12 A (10a.), Semanario Fudicial de la Federación y su Gaceta, Décima Época, $t$. II, Febrero de 2018, p. 892. 
Por tanto, el amparo resulta improcedente con relación a cualquier acción llevada a cabo por la Secretaría o las autoridades que colaboran con ésta, para solicitar la publicación de la convocatoria, bajo la lógica de que dichos actos no generan afectación alguna a los interesados en participar en una determinada licitación, ya que no inciden en su esfera jurídica, esto es, en sus derechos tutelados por la ley.

En efecto, como se advirtió, los documentos finales que dicha autoridad remite a la Comisión para la publicación de la convocatoria son del conocimiento del interesado en participar en una licitación desde la referida publicación, por lo que en caso de inscribirse a la licitación, se actualizaría el supuesto de improcedencia consistente en el consentimiento tácito con relación a cualquier tipo de error o violación en dichos actos o en aquellos realizados para su obtención. ${ }^{30}$

Resulta necesario detenerse en este punto para analizar uno de los actos que la Secretaría, en ejercicio de sus atribuciones emite y que constituye parte de los documentos finales a los que se ha hecho referencia: los criterios de precalificación.

Como se mencionó, los criterios de precalificación son los elementos técnicos, financieros, de ejecución y de experiencia que los interesados en participar en una licitación deberán acreditar en la etapa correspondiente. Ello, con la finalidad de poder pasar a la siguiente etapa correspondiente a la adjudicación de contratos.

Los criterios de precalificación se establecen en función de las características propias de las áreas contractuales que habrán de licitarse. Lo anterior, con la finalidad de que quienes los acrediten sean sólo aquellos participantes que cuenten con las capacidades suficientes para asumir un proyecto con los riesgos y costos que conlleva y con ello, brindar certeza del cumplimiento de las obligaciones previstas en los contratos.

30 Se entiende así ya que la inscripción a la licitación es la forma en que el interesado externó su consentimiento respecto de dichas actuaciones cuyo resultado se ve traducido en lo publicado. Refuerza lo anterior el siguiente criterio: Tesis: 1a./J. 34/2008, Semanario Fudicial de la Federación y su Gaceta, Décima Época, $t$ XXVIII, Julio de 2008, p. 48. 
Al respecto, puede darse el caso en el que algún participante en una determinada licitación manifieste que los criterios de precalificación establecidos son excesivos o de imposible acreditación. A primera vista, dicha situación podría constituir una violación susceptible de ser invocada vía amparo, ya que los participantes que no acrediten dichos elementos en la etapa correspondiente, no podrán continuar en el procedimiento de licitación y, en consecuencia, no serán ganadores del o las áreas contractuales por las que participaron, situación que trascenderá al resultado del fallo.

Los criterios aludidos son establecidos por dicha Secretaría previo a la licitación; no obstante, se hacen del conocimiento del público en general, mediante la publicación de la convocatoria y las bases de licitación, documento éste último que contiene dichos criterios. La etapa de precalificación se desarrolla durante la licitación y no antes, y es justo en ésta en la que se da el primer acto de aplicación de dichos criterios a los interesados, por lo que será hasta ese momento que la autoridad determinará a los sujetos que cumplieron con los mismos. De ahí la insistencia en que para efectos del amparo, las violaciones intraprocesales son aquellas realizadas a partir del inicio y hasta la conclusión de una licitación, no antes.

En consecuencia, los actos de autoridad llevados a cabo durante esta etapa no son impugnables vía amparo indirecto.

\section{Actos durante el procedimiento de licitación}

De manera previa, se analizaron cada una de los actos que conforman el procedimiento de licitación, el cual inicia con la publicación de la convocatoria y las bases correspondientes y finaliza con la suscripción de el o los contratos adjudicados.

Por tanto, es posible afirmar que dichos actos son a los que la ley califica como intraprocesales porque se desarrollan dentro de una licitación. 
Una vez señalado lo anterior, es indispensable entender la lógica bajo la cual resulta improcedente el amparo respecto de cada uno de dichos actos en lo individual, de tal suerte que las violaciones en que pudo haber incurrido la autoridad durante su desarrollo sólo podrán invocarse al controvertir el fallo, demostrando que dicha violación fue de tal trascendencia que afectó el resultado del mismo.

Así, se tiene que entre los objetivos de la reforma energética destacan el atraer mayor inversión al sector energético mexicano para impulsar su desarrollo así como el contar con un mayor abasto de energéticos a mejores precios. Para su realización, una de las acciones claves son las licitaciones para adjudicar contratos. Como se mencionó, para que este procedimiento sea un éxito resulta indispensable que el Estado, a través de la Secretaría de Energía lleve a cabo una adecuada selección de las áreas contractuales a licitar, lo que implica que cuenten con el potencial y características tales que incentiven el interés de los inversionistas, así como elegir el modelo de contratación que genere los mayores beneficios al Estado y a los futuros contratistas, que debe verse reflejado en la reducción de las cargas administrativas y trámites engorrosos.

A la par, el Estado debe contar con un procedimiento de licitación ágil y expedito, sin que ello se traduzca en flexibilizar dicho procedimiento a niveles de corrupción, lo cual permitirá una mayor participación de la industria. Lo anterior, también se traduce en un procedimiento que marche sin interrupciones generadas por la promoción de tantos amparos como etapas tenga el mismo, que implique el suspenderlo en repetidas ocasiones.

Por ello, de actualizarse una posible violación durante el desarrollo $^{31}$ de la licitación, ésta sólo podrá impugnarse hasta que se emita el fallo correspondiente, demostrando que dicha violación trascendió al resultado de éste.

$31 \mathrm{Al}$ respecto, resulta importante destacar que en la exposición de motivos de la Ley de Hidrocarburos no se establece explicación alguna con relación a la procedencia del amparo. 
Lo anterior, permite entender la razón por la cual la Ley de Hidrocarburos realiza la distinción entre aquellos actos intraprocesales y el fallo, y la fase del procedimiento de licitación en la que podrá interponerse el amparo indirecto.

Ahora bien, es de resaltar que todo el procedimiento de licitación está caracterizado por la transparencia en su ejecución, puesto que a través de la página oficial Rondas México, los interesados en participar en una licitación y el público en general, pueden dar seguimiento a cada una de las etapas que lo conforman y de esa manera conocer la convocatoria, las bases de licitación, los contratos, identificar las fechas para la realización de las diversas actividades previstas así como las modificaciones sustanciales a estos documentos. ${ }^{32}$

Lo anterior, constituye un elemento fundamental que aminora los riesgos de que la Comisión, responsable de conducir el procedimiento de licitación, incurra en violaciones durante el mismo, puesto que su actuar puede ser vigilado mediante el mecanismo referido.

Ahora bien, durante la licitación existe una etapa en la que los interesados ${ }^{33} \mathrm{O}$ licitantes ${ }^{34}$ pueden formular preguntas o aclaraciones con relación a aspectos particulares del procedimiento: acceso

$32 \mathrm{Al}$ respecto, son dignos de reconocer los esfuerzos de la Comisón por mejorar la transparencia de su actuar con relación a la administración de los contratos petroleros. De tal suerte que en fechas recientes, dicho órgano publicó en su página oficial los resultados del estudio realizado por el Natural Resource Governance Institute (NRGI) respecto a las mejores prácticas internacionales para la transparencia en la administración de contratos, en el que realiza una serie de recomendaciones a fin de mejorar la trasparencia en la información publicada en el sitio Rondas México. Los resultados referidos podrán ser consultados en el siguiente vínculo electrónico: <https://www.gob.mx/cnh/documentos/relacion-con-ong-s?idiom=es $>$, [15-agosto-18].

33 Compañía que tiene interés en participar en la licitación conforme a lo establecido en las Bases.

${ }^{34}$ La persona moral que precalificó para participar en la licitación y que posteriormente obtiene la autorización para convertirse en Licitante y poder presentar una propuesta conforme a los requisitos establecidos en las bases. 
al cuarto de datos e inscripción a la licitación, precalificación y conformación de licitantes y, presentación y apertura de propuestas, adjudicación, fallo y contrato.

Respecto al acceso al cuarto de datos e inscripción, las preguntas o aclaraciones podrán versar sobre el procedimiento para realizar el pago y los requisitos para acceder a la información. Si bien los interesados o licitantes pueden formular preguntas relacionadas con temas distintos a los señalados, la autoridad no estará obligada a responderlas.

En cuanto a la precalificación y conformación de licitantes, las preguntas o aclaraciones sólo podrán versar sobre los elementos previstos por la autoridad para precalificar así como la integración o formas de participación que se pretendan.

Finalmente, por lo que hace a la presentación y apertura de propuestas, adjudicación, fallo y contrato, las preguntas o aclaraciones sólo podrán versar sobre los aspectos particulares de cada uno de estos puntos, mismas que podrán consistir sobre fechas para su realización, lugar, forma, así como sobre el contenido de los contratos.

Si derivado de la pregunta o aclaración formulada, la autoridad convocante y en su caso, la responsable del diseño de los contratos determinan la necesidad de realizar algún cambio, lo conducente será la modificación del documento en cuestión: contrato o bases de licitación, la cual será publicada en el sitio oficial referido.

Para determinar la procedencia de las modificaciones referidas, la autoridad competente, la Comisión o la Secretaría, habrán de considerar varios elementos: Que sea acorde con la normatividad aplicable, que resulte en beneficio del Estado, en términos de producción y garantía de abasto de hidrocarburos, su viabilidad dadas las características de las áreas a licitar y el objeto del contrato (si éste es para la exploración y extracción o sólo para ésta última actividad) así como la modalidad de contratación, puesto que el contenido del contrato varía en función de las características propias de cada una 
de las modalidades de contratación, así como otros criterios propios del cambio en cuestión.

La publicación de las modificaciones referidas tiene por objeto que los interesados y licitantes las conozcan, ya que éstas formarán parte del documento objeto de dicha modificación -bases o contratos-, por lo que será responsabilidad de los participantes conocer, revisar, analizar y considerar dicha información para efecto del desarrollo de la licitación.

Prever el desarrollo de esta etapa, incentiva la participación de los posibles interesados y permite evitar impugnaciones como resultado de violaciones que dejen en estado de indefensión al quejoso, puesto que las inquietudes de los participantes son escuchadas, analizadas y contestadas por la autoridad, siempre en estricto apego al principio de legalidad que rige su actuar.

Ahora bien, de los procesos licitatorios a la fecha desarrollados, se desprende que el acceso al cuarto de datos constituye una de las etapas que más dudas generan a los interesados y licitantes ${ }^{35}$, puesto que implica realizar un pago para acceder a la información de las áreas contractuales a licitar, la cual es resguardada por la Comisión en ejercicio de la atribución conferida por ley, ya comentada con anterioridad.

Entre las principales dudas generadas destacan las relacionadas con el procedimiento a seguir para llevar a cabo el pago referido así como el trámite a realizar para obtener una licencia y el tipo de información disponible, requisitos indispensables para estar en aptitud de solicitar el acceso a la información en resguardo de la Comisión.

Todas estas dudas y demás preguntas que surjan en torno a esta y cualquier otra etapa dentro del procedimiento de licitación pueden ser formuladas a la autoridad convocante, misma que dará la

35 Esta información puede ser consultada en la página de Rondas México, en el apartado de Aclaraciones que se despliega por cada Ronda que se consulta. 
atención correspondiente, en los plazos y términos señalados en las bases de cada uno de los procesos licitatorios.

Por otro lado, resulta importante señalar que las bases de cada una de las convocatorias a la fecha publicadas ${ }^{36}$ establecen que al finalizar cada etapa de la licitación se levante un acta, misma que debe ser firmada por los integrantes del Comité Licitatorio ${ }^{37}$ así como por los interesados y licitantes que en ellas intervengan, previendo que la falta de dicha firma no afectará la validez del acto en cuestión.

Lo anterior, es relevante puesto que la firma del acto implica un consentimiento expreso del mismo, ya que este acto se traduce en convalidar cualquier tipo de violación cometida, un elemento más que aminora las posibilidades de promover un amparo por violaciones intraprocesales. ${ }^{38}$

Lo señalado refuerza lo ya dicho respecto a que las violaciones cometidas durante el desarrollo de los actos intraprocesales deben ser las menos, esto es, no cualquiera sino sólo aquellas de tal magnitud que trasciendan al resultado del fallo, podrán ser impugnadas.

Una vez aclarado lo anterior, y tomando en consideración que el amparo sólo resulta procedente contra el fallo, los actos intermedios a éste descritos con anterioridad, en los que existan posibles viola-

36 Cada una de las convocatorias son publicadas en el sitio oficial denominado Rondas México: <rondasmexico.gob.mx>. Cabe señalar que a la fecha han concluido nueve procedimientos licitatorios. Si bien las Rondas 3.2 y 3.3 se encontraban aún en proceso, a solicitud de la Secretaría de Energía, la Comisión Nacional de Hidrocarburos determinó cancelarlas, al quedar sin materia.

37 Es el grupo de servidores públicos de la Comisión responsables de coordinar y ejecutar la licitación, conforme a lo establecido en las bases.

38 Dicha firma puede llegar a constituir el consentimiento expresado por escrito, que permite revelar de manera evidente que la persona está conforme con la decisión y consecuencias integrales que implican el acto de autoridad reclamado, elementos que se desprenden del siguiente criterio: Tesis: 2a./J. 8/2018 (10a.), Gaceta del Semanario Fudicial de la Federación, t. I, Febrero de 2018, p. 626. 
ciones, deberán aducirse al impugnar el fallo en cuestión, demostrando que éstas fueron tales que trascendieron al mismo.

Ahora bien, respecto a la suspensión del acto reclamado, Burgoa la define como "el acontecimiento (acto o hecho) o aquella situación que generan la paralización o cesación temporalmente limitadas de algo positivo, consistente en impedir para lo futuro el comienzo, el desarrollo o las consecuencias de ese 'algo', a partir de dicha paralización o cesación; sin que se invalide lo anteriormente transcurrido o realizado". ${ }^{39}$

Como se advierte, la suspensión implica paralizar el acto reclamado con la finalidad de que éste deje de producir sus efectos, de tal suerte que la materia del amparo no se pierda al dejar de existir el acto objeto de reclamación, lo que significa mantener las cosas en el estado de guardaban al momento de que se decrete.

En términos de la Ley de Amparo, la suspensión procede siempre que lo solicite el quejoso y no se siga perjuicio al interés social ni se contravengan disposiciones de orden público.

$\mathrm{Al}$ respecto, Ley de Hidrocarburos establece que los actos relacionados con el procedimiento de licitación y adjudicación de contratos se consideran de orden público e interés social.

Tal como se advierte, la suspensión de los actos relacionados con el procedimiento de licitación resulta improcedente, puesto que no se cumple con uno de los requisitos de procedibilidad previstos en la ley de la materia, pues de decretarse, se contravendrían disposiciones de orden público y se depararía un perjuicio al interés social.

De igual maneral, la Ley que regula el funcionamiento de la Comisión, señala de manera expresa que las normas generales así como los actos u omisiones de los Órganos Reguladores no serán objeto de suspensión. ${ }^{40}$ Solamente en los casos en que impongan

39 Burgoa Orihuela, Ignacio, El juicio de amparo, México, Distrito Federal, Porrúa, 2006, $41^{\circ}$ Edición, p. 804.

40 Véanse las siguientes Tesis: IV.2o.A.124 A (10a.), Semanario fudicial de la Federación y su Gaceta, Décima Época, t. IV, Junio de 2016, p. 2970; PG.IV.A. J/8 
multas, éstas se ejecutarán hasta que se resuelva el juicio de amparo que, en su caso, se promueva.

Como se analizó, uno de los actos generales que la Comisión, en su carácter de Órgano Regulador puede emitir, es el fallo de la licitación, el cual como establece la disposición anteriormente citada no puede ser objeto de suspensión.

Lo anterior, se traduce en que la admisión del juicio de amparo indirecto no supone la suspensión del acto que se reclame, ya que el decretarla sería elemento suficiente para la procedencia del recurso contra el auto que la decrete.

En el caso del procedimiento de licitación, como se ha dicho, el amparo podrá promoverse contra el fallo que se emita, por lo que el único acto que podría ser suspendido es éste y no así aquellos que son efecto o consecuencia del mismo, tales como la suscripción del contrato o el cumplimiento de las obligaciones contractuales correspondientes. ${ }^{41}$

Son dos las razones, una propia de la naturaleza de la suspensión consistente en que, en principio, esta medida no puede tener efectos restitutorios y, la segunda, reside en que los actos referidos son de orden público e interés social, puesto que suscribir el contrato y el cumplimiento de las obligaciones previstas en él permitirá la obtención de ingresos para el Estado y así garantizar el abasto de los energéticos y que las inversiones del contratista no se vean mermadas por cuestiones ajenas al proyecto.

En consecuencia, tal como se ha expuesto, el amparo indirecto es el mecanismo de defensa que resulta procedente contra las violaciones que la autoridad responsable de conducir el procedimiento de licitación haya cometido, el cual deberá presentarse una vez

A (10a.), Gaceta del Semanario Fudicial de la Federación, Décima Época, t. II, Abril de 2015, p. 1261; 2a./J. 22/2003, Semanario Fudicial de la Federación y su Gaceta, Novena Época, $t$. VII, Abril de 2003, p. 196.

41 Tesis: 2a./J. 88/2018 (10a.), Semanario fudicial de la Federación, Décima Época, ubicada en publicación semanal. 
emitido el fallo, sea que las violaciones se hayan cometido en la emisión de dicho fallo o éste se encuentre viciado como resultado de las violaciones intraprocesales. Finalmente, quedó expuesto que el amparo no resulta procedente contra los actos realizados de manera previa al inicio del procedimiento de licitación.

\section{LEGITIMADOS PARA PROMOVER EL JUICIO DE AMPARO}

La Ley de Amparo establece los sujetos que pueden promover un juicio de amparo, a saber:

\section{Quejoso}

Entendido como el titular de un derecho subjetivo - interés jurídico- o de un interés legítimo individual o colectivo, en este último caso, siempre que exista una afectación real y actual a su esfera jurídica, ya sea de manera directa o en virtud de su situación especial frente al orden jurídico.

Como se advierte, la nueva ley amplía el concepto de quejoso, puesto que reconoce que pueden instar dicho juicio aquellos que demuestren tener un interés jurídico o bien, quienes acrediten un interés legítimo.

Mientras que el interés jurídico implica la existencia de un derecho reconocido en una ley, ser titular de dicho derecho, es decir, la facultad de exigencia para su respeto y la obligación correlativa a esa facultad de exigencia ${ }^{42}$, el interés legítimo implica una afectación real y actual a la esfera jurídica de quien lo demanda, dada la situación especial que presenta frente al orden jurídico. ${ }^{43}$

42 Cfr. Zaldivar Lelo de Larrea, Arturo, Hacia una nueva Ley de Amparo, México, Distrito Federal, UNAM-IIJ, 2016, $1^{\circ}$ reimp., p. 44.

43 Cfr. La Ley de Amparo en lenguaje llano, <https://www.scjn.gob.mx/ sites/default/files/pagina/documentos/201611/LibroLeydeamparoenlenguajellano_0.pdf>, [21-agosto-2018] 
A mayor abundamiento, respecto al interés legítimo, se define como un agravio no personal ni directo, sino una situación excepcional $^{44}$ consistente en un interés personal, individual o colectivo, cualificado, ${ }^{45}$ actual, real y jurídicamente relevante, que puede llegar a constituirse en un beneficio jurídico a favor del quejoso derivado de una afectación a su esfera jurídica en sentido amplio (económica, profesional, salud pública). ${ }^{46}$

La diferencia entre el 'interés jurídico' y el 'legítimo' grosso modo es que el primero se refiere a agravios directos a la esfera de derechos y obligaciones personales del quejoso; en cambio, el 'legítimo' permite extender la esfera protectora del amparo a lesiones indirectas a la esfera jurídica y aun a situaciones grupales jurídicamente tuteladas, ocasionadas por la autoridad. Por eso es incorrecto denominar a este principio de legitimación activa como de 'agravio personal y directo', y proponemos denominarlo simplemente 'agravio personal'. Desde luego, no sin considerar que 'actos o resoluciones provenientes de tribunales', como indica la fracción I del artículo 107 constitucional, quien desee promover amparo en su contra deberá estar respaldado por un interés jurídico $[\ldots]^{47}$

Para efectos del amparo, uno de los criterios recientemente adoptados por el Poder Judicial de la Federación alude a la finalidad del

44 Como el caso de la desaparición de áreas verdes comunes, derivado de la autorización de una construcción en determinado predio, respecto del cual no se dio participación a los residentes. En este caso el gobernado acredita ser propietario de un lote ubicado en el lugar afectado y la afectación es a su derecho de audiencia previa.

45 Significa la pertenencia a una categoría definida y limitada. Ejemplos: comerciantes, usuarios de un servicio, o grupo de vecinos.

46 Tesis: 1a./J. 38/2016, Semanario Fudicial de la Federación y su Gaceta, Décima Época, t. II, Agosto de 2016, p. 690.

47 Ferrer Mac Gregor Poisot, Eduardo, op. cit., p. 25. El autor señala que esta nueva legitimación ampliada en el juicio de amparo, si bien extiende la esfera protectora, no es al grado de hacerlo una acción popular que cualquiera pueda ejercer, razón por la que la legitimación activa requiere un agravio personal, lo que comprende tanto al interés jurídico como al legítimo. 
reconocimiento de dicho interés, consistente en reconocer la facultad para impugnar la actuación o la omisión de una autoridad en orden a la afectación que ello le genera, al no acatar lo previsto por determinadas disposiciones jurídicas que le reportan una situación favorable o ventajosa. ${ }^{48}$

Algunos elementos para reconocer el interés legítimo, son los siguientes: ${ }^{49}$

- Titularidad del interés: Una persona o un grupo de personas.

- Poder de exigencia del titular: No puede exigirse una prestación para así sino sólo se puede exigir que la autoridad actúe conforme a la ley, porque la violación a ésta produce una afectación a su situación; su cumplimiento, un beneficio o una ventaja jurídica.

- Norma de la que surge: Se crea para salvaguardar intereses generales, el orden público o el interés social.

- Tipo de afectación que sufre el titular del interés: La afectación se produce de manera indirecta, lo que implica que no es una lesión a la persona sino a la comunidad, pero que impacta calificadamente a un grupo de personas que pertenecen a esa comunidad por la posición que guardan frente al acto ilícito.

Por tanto, para efectos del amparo, el quejoso podrá ser aquel que acredite un interés jurídico o legítimo, con la posibilidad de que éste último pueda ser individual o colectivo.

48 Tesis: I.4o.A.3 K, Semanario fudicial de la Federación y su Gaceta, Décima Época, t. 3, Noviembre de 2012, p. 1908.

49 Tesis: I.8o.A.4 K, Semanario Judicial de la Federación y su Gaceta, Décima Época, t. 3, Mayo de 2013, p. 1888. 
2. Legitimados para PROMOVER EL JUICIO DE AMPARO DENTRO DEL PROCEDIMIENTO DE LICITACIÓN

La legitimación para promover el juicio de amparo está directamente relacionada con el tipo de derechos que, en su caso, el procedimiento de licitación puede otorgar a los que participan.

$\mathrm{Al}$ respecto, la participación en un procedimiento licitatorio no puede implicar el derecho a la adjudicación de un contrato, de serlo, dicha licitación dejaría de observar uno de los principios que la rigen consistente en la competitividad, el cual implica que sólo aquél participante que demuestre tener las capacidades suficientes para hacer frente a un proyecto pueda ser el ganador y por ende, a quien se le adjudique un contrato.

Por tanto, como lo ha sostenido nuestro máximo tribunal, el derecho que deriva de una licitación es precisamente el poder participar en el mismo, velando porque la autoridad respete los principios rectores de dicha licitación. ${ }^{50}$

Con relación al procedimiento de licitación para la adjudicación de contratos, como se mencionó con anterioridad, existen dos tipos de sujetos, el interesado y el licitante. El interesado tendrá tal carácter hasta el acto de inscripción a la licitación, momento en el cual se constituirá en licitante, esto es, en un participante en dicho procedimiento.

Lo anterior, es relevante puesto que el interesado que pretenda promover el juicio de amparo, alegando posibles violaciones durante el procedimiento de licitación estará en actitud de hacerlo en razón del interés legítimo que demuestre tener y no así de un interés jurídico, ya que al no participar en el procedimiento de licitación,

50 Cfr. Tesis: 189052. 2a , Semanario Fudicial de la Federación y su Gaceta, Novena Época, t. XIV, Agosto de 2001, p. 240. 
no tiene como tal un derecho adquirido. Dicho criterio ha sido reconocido por nuestro máximo tribunal. ${ }^{51}$

En efecto, no tener el carácter de participante en la licitación implica el ubicarse en un supuesto distinto a quien sí participó, pues mientras éste último tuvo la posibilidad de ser ganador de uno o varios contratos, el interesado no tiene tal posibilidad por lo que tampoco puede hablarse de una violación a un derecho que no se configuró, razón por la que su interés recae en que el procedimiento licitatorio sea conducido con transparencia, en igualdad de condiciones, competitivo y sencillo.

Lo anterior, implica un interés legítimo pues se trata de una afectación real y actual, ya que la norma mandata que la licitación para adjudicar contratos se lleve a cabo observando una serie de requisitos que, al no haber sido cumplidos por la autoridad, constituyen el motivo suficiente para dejarlo en un estado de indefensión, sólo por citar un ejemplo.

Otra situación en la que puede actualizarse el interés legítimo es aquella en la que se acredite que dados los términos bajo los cuales fue diseñado un determinado contrato, se han generado mayores beneficios para el licitante ganador que para los intereses del Estado, hablando de producción, abasto de hidrocarburos así como de maximización de los ingresos de la Nación.

No obstante, el diseño de cada uno de los contratos está pensado para velar por los intereses del Estado, de tal forma que su adjudicación signifique la mejor oportunidad en cuanto a la continuidad en el desarrollo de las actividades de exploración y extracción así como en los resultados de las mismas.

Las últimas rondas han sido ejemplo de ello: altos ingresos que el Estado percibirá como resultado del número importante de áreas contractuales adjudicadas; el hecho de que a la fecha no se ha pre-

51 Tesis: I.4o.A.589 A, Semanario Fudicial de la Federación y su Gaceta, Novena Época, $t$. XXVI, Julio de 2007, p. 2556. 
sentado impugnación alguna contra los contratos ya suscritos ni instancia de solución de controversias accionada para resolver disputas en el marco de éstos.

Por tanto, el carácter de quejoso para efectos del presente artículo lo tiene tanto el interesado como el licitante que hubiese participado en dicho procedimiento y que el fallo le depare una afectación, esto es, que acrediten tener un interés jurídico o legítimo.

Toda vez que la situación especial del interesado ya fue analizada, a continuación se revisará la situación de quien a primera vista, puede alegar una posible afectación a su interés jurídico: El Licitante. $\mathrm{Al}$ respecto, se advierten dos posibles escenarios:

a) Licitante ganador

b) Licitante no ganador

\section{A) LICITANTE GANADOR}

El carácter de licitante ganador lo tiene quien fue declarado ganador de la licitación para una o más de las áreas contractuales según corresponda, en términos de las bases y la normatividad aplicable y que por ese hecho asume los derechos y obligaciones previstos en el contrato.

Al respecto, no se advierte la posible afectación que en su caso puede hacer valer dicho sujeto mediante amparo, puesto que al firmar el contrato consiente de manera expresa lo actuado durante el procedimiento, de tal modo que se actualiza una causal de improcedencia por actos consentidos expresamente o por manifestaciones de voluntad que entrañen ese consentimiento.

Atento a lo anterior, partiendo del supuesto de que el licitante al que le ha sido adjudicado un contrato, el cual ha iniciado los actos tendentes a cumplir con el mismo, ha manifestado de esa forma su voluntad de sujetarse a los términos de dicho contrato, no podría impugnar dicho instrumento, alegando violaciones previas 
al inicio y durante el procedimiento de licitación correspondiente. Primeramente, porque podría hacerse valer la causal referida, al señalar que la firma del contrato y los actos realizados con posterioridad implican manifestaciones de su voluntad en el sentido de que ha consentido los actos reclamados. Segunda, porque el propio contrato prevé los mecanismos para resolver cualquier controversia surgida en el marco del mismo, por lo que el quejoso tendría que desahogarlos previamente, atendiendo al principio de definitividad que rige en el juicio de amparo.

Sirve a lo anterior lo previsto en la Ley que rige a los Órganos Reguladores $^{52}$, la cual establece respecto a las decisiones fundadas y motivadas que sean aprobadas por éstos, la imposibilidad de alegar un daño o perjuicio en la esfera económica por aquéllos que realicen las actividades reguladas.

\section{B) LiCITANTE NO GANADOR}

Con relación al licitante no ganador que impugne el fallo por violaciones cometidas en éste, o en los actos previos al mismo, la carga jurídica consistirá en demostrar su dicho, que las violaciones alegadas lo dejaron en estado de indefensión o que son de imposible reparación. No obstante, como se señaló, en caso de que dicho quejoso pretendiera suspender la ejecución de los actos posteriores a la emisión del fallo, ésta resultaría improcedente por disposición expresa de la ley.

Como se señaló, la autoridad convocante previsora de posibles impugnaciones, ha diseñado diversos mecanismos cuya finalidad es que los interesados y licitantes puedan manifestar todo tipo de inquietudes con relación a los diversos actos de la licitación -etapas para formular dudas y aclaraciones-, así como la realización de talleres para explicar y/o puntualizar los temas que se estimen pertinentes,

\footnotetext{
52 Artículo 27 in fine de la ley citada.
} 
lo cual incidirá en el número de posibles quejosos y en las posibles violaciones que se hagan valer.

No debe perderse de vista lo comentado en el apartado anterior, en el sentido de que, al concluir cada una de las etapas del procedimiento de licitación, suele firmarse un acta, tanto por la autoridad como por los participantes, por lo que ello podría constituir una manifestación más del consentimiento de los actos realizados durante dicha licitación.

Lo anterior, permite sostener que el procedimiento de licitación ha sido fortalecido con los diversos mecanismos ya descritos, de tal manera que si bien, es inevitable una posible impugnación, dados los intereses que cada parte pueda tener en lo particular, su procedencia y el resultado exitoso del mismo son una cuestión totalmente distinta que no está garantizada.

\section{v. Conclusiones}

El amparo es una herramienta jurídica, que permite a los gobernados defenderse de los actos de autoridad que violentan su esfera jurídica. Como se ha mencionado en el presente artículo, la licitación para la adjudicación de contratos, es un proceso que se integra por diversas etapas, en las que concurren actos de diversas autoridades.

Pero de acuerdo a lo señalado en el presente artículo, no todos los actos desplegados por las autoridades, pueden ser combatidos mediante la figura del amparo, como son los actos previos al inicio del procedimiento de licitación, esto bajo la lógica de que dichos actos no generan afectación alguna a los interesados en participar en una determinada licitación, ya que no inciden en su esfera jurídica, esto es, en sus derechos tutelados por la ley o en su caso resultan convalidados por el gobernador (interesado en participar en la licitación) al momento de la inscripción en la licitación.

Por lo que hace a los actos realizados durante el procedimiento de licitación, como se ha señalado, por ley sólo podrá impugnarse la 
que ponga fin al mismo, por violaciones cometidas en la resolución o durante el procedimiento.

Así tememos que el amparo indirecto es el mecanismo jurisdiccional procedente únicamente contra la decisión final adoptada en el procedimiento de licitación para la adjudicación de contratos. No obstante, resulta improcedente respecto de los actos previos al inicio de dicho procedimiento y aquellos denominados intraprocesales.

\section{Vi. Bibliografía}

Burgoa Orihuela, Ignacio, El juicio de amparo, México, Distrito Federal, Porrúa, 2006, $41^{\circ}$ Edición.

Caballero Ochoa, José Luis, La cláusula de interpretación conforme y el principio por persona (Artículo $1^{a}$ segundo párrafo de la Constitución), Distrito Federal, IIJ, 2011.

Contratos Petroleros. Cómo leerlos y entenderlos. OpenOil, traducción al español 2013.

Ferrer-Mac Gregor Poisot, Eduardo, Panorámica del derecho procesal constitucional y convencional, México, Marcial Pons-IIJ, 2017.

- Eduardo, El nuevo juicio de amparo y el proceso penal acusatorio, México, UNAM-IIJ, 2013.

Radon, Jenik, The ABCs of Petroleum Contracts: License-Concession Agreements, foint Ventures, and Production-sharing Agreements, New York, Covering Oil.

Salgado Ledesma, Eréndira, Manual de Derecho Procesal Constitucional, Ciudad de México, Porrúa, 2011.

Zaldivar Lelo de Larrea, Arturo, Hacia una nueva Ley de Amparo, México, Distrito Federal, UNAM-IIJ, 2016, $1^{\circ}$ reimpresión.

\section{REFERENCIAS ELECTRÓNICAS}

Semanario Judicial de la Federación < https://sjf.scjn.gob.mx>

Rondas México < rondasmexico.gob.mx> 
Suprema Corte de Justicia de la Nación

La Ley de Amparo en lenguaje llano, <https://www.scjn.gob.mx/sites/ default/files/pagina/documentos/201611/LibroLeydeamparoenlenguajellano_0.pdf>. 